\title{
Erratum to: Using a gradient in food quality to infer drivers of fatty acid content in two filter-feeding aquatic consumers
}

James H. Larson ${ }^{1} \cdot$ William B. Richardson ${ }^{1} \cdot$ Jon M. Vallazza $^{1} \cdot \operatorname{Lynn}_{\text {A. Bartsch }}{ }^{\text { }}$ Michelle R. Bartsch ${ }^{1}$

Published online: 6 July 2017

(c) Springer International Publishing AG 2017

\section{Erratum to: Aquat Sci}

DOI 10.1007/s00027-017-0537-0

In the original publication Table 5 was displayed incorrectly. The three columns on the right are not correctly aligned with the column head. The correct table is as follows:

The online version of the original article can be found under doi:10.1007/s00027-017-0537-0.

James H. Larson

jhlarson@usgs.gov

1 U.S. Geological Survey, Upper Midwest Environmental Sciences Center, 2630 Fanta Reed Road, La Crosse, WI 54650, USA 
Table 5 Components identified by partial least squared regression (PLSR) analysis as strongly relating to the identified consumer fatty acid characteristic

\begin{tabular}{|c|c|c|c|c|}
\hline \multicolumn{2}{|c|}{ 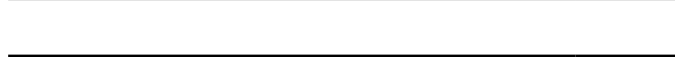 } & \multirow{2}{*}{$\frac{\text { CF } \omega 6 \text { (comp 1) }}{43.4}$} & \multirow{2}{*}{$\begin{array}{l}\text { DM } \omega 3: \omega 6 \text { (comp 1) } \\
18.7\end{array}$} & \multirow{2}{*}{$\begin{array}{l}\mathrm{DM} \omega 3: \omega 6(\operatorname{comp} 2) \\
50.1\end{array}$} \\
\hline$\%$ Variance explained (predi & rs) & & & \\
\hline$\%$ Variance explained (respc & & 42.9 & 78.4 & 84.1 \\
\hline Predictor variable category & Predictor variable & & Loadings & \\
\hline Seston & Chlorophyll $a$ & - & 0.32 & - \\
\hline Seston & $\delta^{13} \mathrm{C}$ & - & - & - \\
\hline Seston & $\delta^{15} \mathrm{~N}$ & - & - & - \\
\hline Seston & $\sum \mathrm{FA}$ & -0.24 & - & 0.31 \\
\hline Seston & PUFA & -0.24 & - & 0.32 \\
\hline Seston & $\mathrm{UI}$ & -0.24 & - & 0.32 \\
\hline Seston & $n-3$ & -0.24 & - & 0.31 \\
\hline Seston & $\mathrm{n}-6$ & -0.21 & - & 0.32 \\
\hline Seston & $n-3: n-6$ & - & - & - \\
\hline Seston & Algal FAs & -0.24 & - & 0.32 \\
\hline Seston & Bacterial FAs & -0.24 & - & 0.30 \\
\hline Seston & $14: 0$ & - & - & - \\
\hline Seston & $15: 0$ & -0.23 & - & 0.31 \\
\hline Seston & $16: 0$ & -0.24 & - & 0.31 \\
\hline Seston & $16: 1 \mathrm{n}-7$ & -0.24 & - & 0.28 \\
\hline Seston & $17: 0$ & -0.24 & - & 0.30 \\
\hline Seston & 17:0iso & -0.23 & - & 0.29 \\
\hline Seston & $18: 0$ & -0.25 & - & 0.30 \\
\hline Seston & $18: \ln -7$ & - & - & - \\
\hline Seston & $18: 1 \mathrm{n}-9 \mathrm{c}$ & - & - & 0.28 \\
\hline Seston & $18: 2 \mathrm{n}-6 \mathrm{c}(\mathrm{LIN})$ & - & - & 0.30 \\
\hline Seston & $18: 3 n-3($ ALA) & -0.23 & - & 0.32 \\
\hline Seston & $20: 2 n-6$ & -0.23 & - & 0.32 \\
\hline Seston & $20: 4 n-6$ (ARA) & - & - & 0.25 \\
\hline Seston & $20: 5 n-3$ (EPA) & -0.24 & - & 0.29 \\
\hline Seston & 22:6n-3 (DHA) & -0.21 & - & 0.32 \\
\hline Water quality & Conductivity & - & 0.31 & - \\
\hline Water quality & Dissolved oxygen (\%) & - & - & - \\
\hline Water quality & Dissolved oxygen (mg/L) & - & - & - \\
\hline Water quality & Water temperature & - & - & - \\
\hline Water quality & $\mathrm{pH}$ & - & - & - \\
\hline Water quality & SRP & - & 0.29 & - \\
\hline Water quality & $\mathrm{NHx}$ & - & - & - \\
\hline Water quality & NOx & - & 0.31 & - \\
\hline Water quality & $\mathrm{TN}$ & - & 0.33 & - \\
\hline Water quality & $\mathrm{TP}$ & - & 0.33 & - \\
\hline Water quality & TN:TP & - & -0.23 & - \\
\hline Water quality & DIN:SRP & - & - & - \\
\hline Land Cover & Watershed area & - & - & - \\
\hline Land Cover & Wetlands & - & - & - \\
\hline Land Cover & Forest & - & -0.28 & - \\
\hline Land Cover & Grasslands & - & 0.28 & - \\
\hline Land Cover & Urban & - & - & - \\
\hline Land Cover & Crops & - & 0.24 & - \\
\hline
\end{tabular}

Consumers are caddisflies (CF) or dreissenid mussels (DM) collected from tributaries and nearshore areas of the Great Lakes. Loadings are equivalent to a correlation between the component and the individual variable. Only loadings of 0.2 or more are shown. Cross-validation supported the inclusion of each of these components

$S E$ seston from the $<35 \mu \mathrm{m}$ fraction, DIN Sissolved inorganic nitrogen 